REsumo
A partir da escrita de um caso
clinico, e focando a questão da
psicose na infância, discorrere-
mos sobre os conceitos lacanianos
de alienação e separação como
fundamentais na construção
subjetiva e no tempo de
estruturação do sujeito, para
uma aproximação à situação da
criança advinda da possibilida-
de do impasse subjetivo como
condição de sofrimento psíqui-
co, em que a criança não sus-
tentaria a direção de sua carga
pulsional.
Descritores: sujeito; Outro;
estruturação subjetiva; psicose;
infância.

\section{SOBRE A \\ CONSTITUIÇÃO DO SUJEITO: \\ O IMPASSE SUBJETIVO}

\title{
Introdução
}

\author{
Cirlana Rodrigues de Souza \\ João Luiz Leitão Paravidini
}


estruturação. Na criança, a ênfase é sobre o termo estruturação, que aponta para o movimento do sujeito no campo da linguagem - o processo do ser, nascido organismo, se constituindo sujeito. Assim, uma expressão como "psicose na criança" não se sustenta quando optamos pela compreensão do processo de constituição do sujeito.

Essa clínica é imperativa: cada criança deve ser tomada em sua singularidade, não sendo possível que se olhe para esse processo buscando algo da ordem de uma etapa esperada, cumprida ou não, pois o que temos é a criança em seu tempo lógico, o da infância, tempo de ela tomar a palavra e responder por essa palavra, conforme De Lemos (2007).

Neste texto, teremos como escopo o caso clínico de um menino de 4 anos. Suas palavras, seus afetos e sua história têm a função de nos ajudar a responder à questão inferida a partir de Lacan: de que trata, então, a psicose da criança? Aqui, trata-se da condição do pequeno Cadu, que, na transferência, nos fisgou pelo não saber.

Partiremos da hipótese de Vorcaro (1999) de que é possível reconhecer, nas manifestações de uma criança, sua condição de estruturação sustentando a lógica da estruturação subjetiva a partir da teoria lacaniana acerca da constituição o sujeito.

$\mathrm{Na}$ construção do caso clínico, a partir das manifestações de fala de Cadu, abordaremos os processos de alienação e separação, elaborados por Lacan, e do tempo de estruturação do sujeito, desenvolvido por Vorcaro, buscando uma aproximação à condição estrutural dessa criança em torno de suas especificidades.

\section{A condição subjetiva da criança}

Quando Lacan aponta para o fato de que a psicose na criança não é a mesma coisa que no adulto, ele instaura uma problemática sobre a estruturação da psicose naquilo que é específico à criança. Dentro da infinitude de questões sobre este tema, uma diz respeito à premissa da psicanálise, na linha das estruturas psíquicas, de que psicose, neurose, perversão (e o autismo, para muitos teóricos) são estruturas psíquicas estabelecidas em um processo de construção subjetiva, no encontro entre o sujeito e o Outro (campo da linguagem) durante seu tempo de infância. Por isso, como sustentar uma psicose 
da criança partindo do fato psíquico de que a criança ainda está inscrita nesse tempo do infantil? As elaborações teóricas que se seguem visam a fundamentar esta questão, precedendo nossa narrativa do caso clínico.

Inicialmente, a proposta é remeter as circunstâncias que afetam a vida da criança à noção de hipótese clínica como alternativa à limitação desta em qualquer condição. Um diagnóstico, como resposta do outro à demanda direcionada da criança, acaba por mantê-la "presa" a significantes que lhe são direcionados, ou seja, a criança é mantida na posição que a impede de tomar a palavra, de fazer laço social; na posição de alienação instaurada em sua constituição. Assim, o diagnóstico é um desserviço à subjetivação.

$\mathrm{Na}$ psicose, trata-se, de modo geral, da problemática frente ao outro e ao campo da linguagem, da questão da identificação e da alteridade, pontos que remetem ao sujeito do inconsciente, ao tema da subjetividade, e significa, conforme Fink (1998), explorar o que é ser sujeito, como alguém se torna um sujeito e as condições responsáveis pelo fracasso dessa operação lógica. Todavia, na criança, algo antecede a esse fracasso propriamente dito, que entendemos como impasses na estruturação psíquica.

Tornar-se sujeito é da ordem do tempo lógico de sua constituição, do tempo da infância e do infantil. Aqui, são as manifestações de fala da criança que apontam para esses impasses na subjetivação.
Diante disso, atentamos para o fato de a psicose ser definida como o fracasso da estruturação subjetiva a partir de Lacan (Fink, 1998), no caso da clínica do adulto, e para o fato de que, para a criança, não há uma estrutura subjetiva pronta (Vorcaro, 1999, 2004, 2008, entre outros). Neste último caso, estamos falando de estrutura não decidida (Bernardino, 2004), o que quer dizer que a subjetivação da criança não está terminada, fazendo-se ainda possível a inscrição de elementos constitutivos advindos do campo do Outro.

No que diz respeito à criança, primeiro, não há sujeito constituído, pronto, e menos ainda um sujeito que possamos definir em posição psicótica; segundo, se a psicose é o fracasso dessa subjetivação, então não há como sustentarmos a expressão "criança psicótica". Assim, as condições de sofrimento psíquico da criança nos apontariam para a instauração, durante o processo de constituição psíquica, de impasses subjetivos: em condições próximas à deriva, sem direção no campo da linguagem, a criança não consegue sustentar-se rumo à subjetivação de sua carga pulsional.

Frente à possibilidade de emergência desse impasse, reconhecido a partir das manifestações clínicas que apontam para o abandono do ser no campo da linguagem; frente às complexas relações com o Outro dificultando o laço social; e frente, também, aos fenômenos de fala denunciando essa estruturação psíquica com tro- 
peços e pontos dissociados na cadeia em que se manifestam, resta-nos propor, como Fink (1998), ferramentas clínicas para causar uma subjetividade, participar ou intervir na construção dessa subjetividade. Nesta proposta, a estrutura de língua ${ }^{1}$ de uma criança é nossa aposta como ferramenta para essa causação na clínica.

Falar em sujeito é falar da suposição de um saber advindo do inconsciente em resposta ao Real de corpo pulsional que faz furo à ordem simbólica. Neste sentido, a teorização lacaniana formaliza essa suposição a partir da noção de estrutura, que comporta quatro elementos: $\$$ (sujeito barrado), S1 (sintoma), S2 (saber) e $a$ (objeto a). Estes elementos estão articulados em um circuito pulsional fundante da construção subjetiva, no caminho que se faz do Real, daquilo do corpo pulsional inscrito no campo da linguagem.

Também, são partes dessa construção os processos de alienação e separação, importantes no que se refere à compreensão do tempo da infância, da inscrição da criança no simbólico que lhe é anterior. Isso posto, Vorcaro (1999) enfatiza a necessidade de levarmos em conta o modo pelo qual o sujeito, como efeito da linguagem e da fala (insubstancial), vincula-se ao ser vivo, à substância gozosa. Ela nos diz:

A estruturação do infans em falante implica mudar algo na substância do ser operando com a linguagem, que não tem substância. As operações de alienação e de separação nos ensinam que o sujeito do inconsciente nasce nessa incidência do Real sobre o Simbólico, ou seja, no destacamento do intervalo vazio entre os significantes, onde a criança reencontra sua perda de ser na incompletude do Outro, na interseção que baliza o sujeito no intervalo entre significantes, a partir do qual a metonímia do desejo se põe em perspectiva. (p. 27, itálicos da autora)

Quando o corpo da criança se faz pulsional pelo atravessamento simbólico como um corte significante, justamente ali também passam a "funcionar" as operações de alienação e separação, o que, conforme suas ocorrências, pode apontar para um possível impasse na subjetivação. Esta possibilidade se apresenta em função do não destacamento entre os significantes, lembrando Lacan ao postular que um sujeito se constitui como um significante para outro significante, sem que, no entanto, ele possa ser identificado ao próprio significante.

\section{Alienação e separação}

Laurent (1997), ao comentar os capítulos sobre alienação e separação em O Seminário, livro 11: os quatro conceitos fundamentais da psicanálise, de Lacan (2008), mostra-nos que esses operadores são tomados como as duas operações constituintes do sujeito e que, até então, Lacan havia falado dos processos metafóricos e metonímicos como funcionamento do inconsciente. Ele nos esclarece algo importante: 
até esse seminário o sujeito era abordado como efeito de significantes; a partir dessas operações de alienação e separação o sujeito é, também, efeito de uma causa, melhor dizendo, sua causação é um objeto perdido no tempo da pulsão: o objeto $a$, resto do Real, o não simbolizado. Assim, o sujeito é efeito e advém de uma causa, duas faltas que são uma.

Dito isso, tomemos Lacan (2008), em que a proposta é dar conta da constituição do sujeito a partir de uma lógica. $\mathrm{Na}$ aula de 20 de maio de 1964, ele expõe, ao final, uma elaboração sobre o sujeito em que, na sequência, acrescerá os elementos de alienação e separação como constituintes. Ele diz: "O sujeito nasce no que, no campo do Outro, surge o significante. Mas por este fato mesmo, isto - que antes não era nada senão sujeito por vir - se coagula em significante" (p. 194). Sujeito nascido no tempo do inconsciente como aquilo que se abre e se fecha. A partir dessa abertura no campo do Outro, instaura-se o processo de constituição do sujeito. Assim, o sujeito não nasce pronto, e o primordial é que essa constituição se dá a partir da relação sujeito e Outro, e dessa relação nos interessam as operações mencionadas.

Outro aspecto dessa constituição apresentado por Lacan (2008) é que o sujeito se "funda" a partir da alienação em que duas faltas se recobrem: a dependência do sujeito ao significante que está no campo do Outro; daí ser esta relação imprescindível e que vem retomar outra falta que é a falta real. ${ }^{2}$ Conforme o autor:

Duas faltas se recobrem. Uma é da alçada do defeito central em torno do qual gira a dialética do advento do sujeito a seu próprio ser em relação ao Outro - pelo fato de que o sujeito depende do significante e de que o significante está primeiro no campo do Outro. Esta falta vem retomar a outra, que é a falta real, anterior, a situar no advento do vivo, quer dizer, na reprodução sexuada. A falta real é o que o vivo perde, de sua parte de vivo, ao se reproduzir pela via sexuada. Esta falta é real, porque ela se reporta a algo de real que é o que o vivo, por ser sujeito ao sexo, caiu sob o golpe da morte individual. (p. 201)

Podemos, assim, considerar que no estatuto da alienação encontramos um "resto que define o ser sexualmente definido do sujeito", e que "o caráter fundamentalmente parcial das pulsões introduz uma falta, que Lacan designa marcando o sujeito com uma barra (\$)” (Laurent, 1997, p. 37). Portanto, o significante é a parte do Outro que tem como efeito o sujeito. 
Para Lacan, o sujeito se funda na alienação e ele nos esclarece que isto não quer dizer que o sujeito está condenado, em sua existência, ao campo do Outro. Para isto, há a segunda operação da falta, a separação. Se tomarmos a psicose do adulto como fracasso na subjetivação, aí parece incidir essa condição do ser se alienando ao campo do Outro, ao saber advindo do Outro, visto que aqui presentifica-se a falta da falta no campo do Outro. Mas, para a criança, essa condição nos conduz ao que chamamos de um impasse, por todas as razões já mencionadas.

Lacan (2008) discorre sobre as operações na relação do sujeito com o Outro, relação que é constitutiva da subjetividade. No caminho da formalização, essas operações são operações lógicas retiradas da "teoria" dos conjuntos, da lógica matemática. Importante é o uso do termo "operações", que nos remete a um ato que tem um efeito: essa operação subjetiva, ato entre seres de linguagem, tem um efeito - o sujeito do inconsciente.

A primeira operação é a alienação, modo singular de encontro entre o sujeito e o Outro. A ênfase de Lacan nessa reunião, nessa junção, é que o fato de estarem reunidos não os torna uma só coisa e esses elementos pertencem simultaneamente a espaços em comum e aos espaços singulares:

O vel da alienação se define por uma escolha cujas propriedades dependem do seguinte: que há, na reunião, um elemento que comporta que, qualquer que seja a escolha que se opere, há por consequência um nem um, nem outro. A escolha aí é apenas a de saber se a gente pretende guardar uma das partes, a outra desaparecendo em cada caso. (Lacan, 2008, p. 206, itálico do autor)

A alienação tem como efeito uma indiferenciação entre o sujeito (o ser) e o Outro (o sentido) no ponto de junção do não sentido, lugar de ausência do sentido onde não é possível haver nem um sujeito e nem outro, o Outro. Nessa operação, ocorre a afânise do sujeito: o sujeito desaparece ali onde há o não senso. Nesse primeiro tempo da relação com o Outro, o ser é impedido, pelo desejo desse Outro, de aparecer, de ser sujeito desejante. Essa supressão antecede a segunda operação, a separação.

Ao definir o Outro como o lugar dos significantes primordiais, sujeito e Outro estão ligados e o sujeito está aí alienado, na medida em que se constitui no espaço do Outro. Porém, essa operação de reunião não é total, posto que o sujeito não é de todo esse significante, não está de todo no campo do Outro, mas, como já mencionamos, 
há uma falta introduzida pelas pulsões parciais que o define como $\$$.

A separação tem a lógica de funcionamento da operação de interseção: o espaço do não sentido é constituído por elementos advindos tanto do sujeito como do Outro. Para Lacan (2008), o sujeito deve, ali onde é desaparecido, ser procurado. Pela via pulsional, responde a duas faltas: a primeira é a falta constitutiva do Outro (ser também desejante, portanto, faltante) e o autor nos mostra o belo questionamento da criança frente a isso, ao discurso alienante do Outro: "ele me dir isso, mas o que é que ele quer". O sujeito reconhece que esse discurso encobre a falta: "O desejo do Outro é apreendido pelo sujeito naquilo que não cola, nas faltas do discurso do Outro e todos os por-quês da criança testemunham ... o enigma do desejo do adulto" (p. 209, itálico do autor).

Uma vez tomada essa falta no Outro (aquele que me constitui também é causado por uma falta), instaura-se a dialética do sujeito e a resposta dele à primeira falta é instaurar uma segunda: pode ele me perder? Pode ele sobreviver sem mim? Dialeticamente, deve ser possível ser perdido e deixar-se perder, conforme Lacan (2008): "Uma falta recobre a outra, daí, a dialética dos objetos do desejo, no que ela faz a junção do desejo do sujeito com o desejo do Outro" (p. 210). Uma falta é resposta à outra e, reconhecida a impreterível incompletude do ser, o sujeito passa, pela ope- ração de separação, a ser desejante, efeito de significantes advindos do Outro e causado pela falta.

\section{O tempo de estruturação do sujeito}

No Seminário de 1974-1975, R.S.I., Lacan propõe a topologia como recurso de uma escrita da constituição do sujeito. $\mathrm{O}$ nó borromeano é a estrutura psíquica, a realidade psíquica do ser constituída de três círculos que se combinam em um entrecruzamento. Para ele, Real, Simbólico e Imaginário são palavras, cada uma tem seu sentido e há uma relação entre elas. Essas relações visam a dar conta das inscrições no que concerne ao não saber, ao inconsciente.

O Real é definido por Lacan (1974-1975) como "o que é estritamente impensável” (p. 3), aquilo que é anterior ao campo da linguagem e, por isto, impossível de fazer sentido; lugar do não sentido, a existência pura. O Simbólico vincula-se à cadeia de significantes que estrutura o inconsciente e faz furo no Real; e o Imaginário é a matéria, a parte consistente que se liga à representação do não saber, ajudando a suportar o não sentido.

Com base nessa topologia borromeana, Vorcaro (2004, 2008) propõe que se compreenda o processo de constituição do sujeito como tecendo um nó, a partir desses três 
registros. Tomando a proposição lacaniana de que um nó borromeu é feito com seis gestos, combinatória possível entre RSI, a autora supõe um entrançamento, cruzamentos de Real, Simbólico e Imaginário, como o tempo lógico de estruturação, processo em que é possível a incidência de acontecimentos que alterariam essa trança, afetando a condição da criança:

Trata-se de seguir a trilha pela qual a unidade biológica de um ser (re)verte o lugar de coisa operada por uma alteridade estruturada, em posição de sujeito estruturado.... A rota deste ponto, mergulhado num espaço que lhe impõe alteridade radical, será descrita, considerando os deslocamentos que intervêm em sua deformação, traçando rupturas e continuidades, que marcam o caráter de sua constituição até que uma estrutura se destaque. Tal destacamento inclui a estrutura da qual partiu, sendo, entretanto, exclusiva, constituindo um precipitado singular. (Vorcaro, 2004, p. 67)

No princípio, o campo da linguagem precede o organismo vivo e lhe oferece os elementos significantes para sua estruturação. ${ }^{3}$ Esses significantes inscrevem as linhas iniciais para a subjetivação. Os gestos, movimentos de estruturação, são, resumidamente, conforme Vorcaro (2004, 2008):

1. A posição z̧ero: posição da criança que antecede o início de sua estruturação psíquica e em que prevalece o real do organismo, real que passará a ser investido de forma imaginária pela alteridade de um 
outro cuidador; inaugura-se uma condição de subjetividade, uma matriz simbólica;

2. O primeiro movimento: incidência do Real sobre essa matriz simbólica; é o tempo lógico do funcionamento simbólico caracterizado pela descontinuidade entre a tensão causada por um real do corpo e o apaziguamento dessa tensão por meio de uma ordem simbólica encarnada pelo outro cuidador. O que demarca esse primeiro movimento é a falta de continuidade entre tensão e apaziguamento;

3. O segundo movimento: momento de reconhecimento do Outro como causador de tensão e privação, de reconhecimento da alteridade, da separação/diferenciação entre a criança e o seu Outro constitutivo. Incidência do Imaginário no Real;

4. O terceiro movimento: momento da estruturação simbólica, quando a criança é tomada como o objeto de desejo da mãe, espécie de substituto para a falta constitutiva. É a criança alienada ao desejo materno, incidência do Simbólico no Imaginário. Vale ressaltar que é nesse momento da estruturação psíquica que aconteceria, pela posição de alienação da criança, o impasse subjetivo, caso não ocorra outra resolução para esse movimento;

5. O quarto movimento: é nesse momento que se pretende uma saída da posição anterior, um movimento de separação, por meio de algo de Real que privaria e interditaria a mãe: incidência do Real no Simbólico, novamente. Podemos inferir que buscar uma saída estrutural, como propomos, incidiria sobre esse quarto movimento, como esse algo de Real;

6. O quinto movimento: entrada de um terceiro, momento de idealização, em que o Imaginário retorna a incidir sobre o Real;

7. O sexto movimento: momento da metáfora paterna, em que o Simbólico incide sobre o Imaginário, de "regulação" entre desejo e lei, ordem simbólica, em que sua posição de objeto do desejo do outro é barrada, prevalecendo a identificação por meio da alteridade.

Em uma articulação com o que abordamos sobre alienação e separação, essas operações caracterizam o modo de funcionamento dos tempos de estruturação no campo da linguagem. Conforme a autora acima citada, nos quatro primeiros tempos, incluindo a posição zero, a criança está posicionada no campo 
do Outro, como seu objeto de desejo; nos três últimos tempos, a criança responde pela significação de suas inscrições e a falta é instaurada pela inscrição da metáfora paterna, ruptura que promove o advento do sujeito constituído.

Detenhamo-nos no ponto em que, nessas operações, se instaura o impasse, quando o campo do Outro não encontra resposta pulsional no sujeito e este não se constitui como ser falante e desejante.

Partindo das operações de alienação e separação introduzidas por Lacan (2008), Vorcaro (1999) explora a questão das psicoses considerando essas operações. A estruturação psíquica é tomada, por Vorcaro, a partir de "modos distintos de se fazer com a linguagem" (p. 26), pela maneira como a criança responde ao Outro: "Basta que a criança constate que esse desejo indeterminado da linguagem lhe diz respeito: que ela não é nada sem essa escolha, que não é nada por causa dessa escolha, que o Outro pode querer perdê-la" (p. 26).

$O$ sujeito nasce da e na linguagem e nesses modos de se fazer na linguagem podem ocorrer impasses, de onde podemos inferir uma possibilidade clínica em direção à psicose, à debilidade, aos fenômenos psicossomáticos e ao autismo.

Interessa-nos, pela pertinência ao nosso caso clínico, compreender o que se passa na psicose a partir de Vorcaro (1999). Retomando as operações de alienação e separação, ela nos mostra o que ocorre na relação sujeito e $\mathrm{Ou}$ tro e que teria como resposta o impasse na subjetivação.

Resumindo, a ênfase é sobre o reconhecimento das faltas constitutivas da lógica alienação-separação e dos desdobramentos desta no tempo de articulação do sujeito. Sem intervalo entre significantes, sem os intervalos do discurso do Outro, como nos mostrou Lacan (2008), não há como instaurar, dialeticamente, o segundo tempo da falta (separação), em que se faz questionar o desejo do Outro:

a criança fica colada ao mandato em que ela é o que falta no Outro. Encarnando essa falta, ela preenche o intervalo entre significantes, na mesma função de qualquer significante: remete-se a outro significante. $\mathrm{Na}$ solidez em que a cadeia significante primitiva é apanhada, a abertura dialética está impedida, e o significante representa outro significante num deslizamento infinito. (Vorcaro, 1999, p. 36, grifo da autora)

Assim, quando não se instaura o tempo da separação, fica comprometida a condição do sujeito como efeito de significantes, pois a criança, quando posta no lugar do objeto do desejo do Outro, não reconhece a falta nesse Outro e não pode responder com sua própria falta. Se não há lugar para as "faltas", isso implicará que não há possibilidade de haver condições de viabilização para o sujeito causado. O que assombra a criança é o destino psicótico como forma de tamponar a falta do Outro. 
Se o deslocamento lógico das operações subjetivas em questão não ocorrer, e se se mantiver a afânise do sujeito atado à posição de objeto do desejo do Outro, sem a interseção efetiva do nome-do-pai, a criança estará implicada em um impasse subjetivo em direção à psicose.

Todavia, a clínica psicanalítica com crianças supõe uma aposta primordial: a lógica da constituição subjetiva de uma criança nos permite instaurar, pela via do campo da linguagem, a falta constitutiva - lógica de um tempo de estruturação permitida pela topologia lacaniana do nó borromeano, em que se entrecruzam Real, Simbólico e Imaginário.

\section{O caso clínico}

O pequeno Cadu chega ao atendimento com a avó materna e ainda não tem 4 anos completos. A cena familiar é afetuosa e o menino, apesar de acolhido nos braços da avó, escapa, se agita, se movimenta, mas não é invasivo e nem agressivo. Parece querer libertar-se do corpo do outro: é difícil ficar junto, fazer laço. Apesar da agitação, ele parece não sair do lugar. A demanda se instala por uma especificidade de Cadu, pois não há nada da ordem do corporal ou de crises agressivas: "não consegue se comunicar, sua fala é repetitiva”. A angústia familiar gira em torno de o menino falar "coisas sem sentido" e estar "sempre 
agitado". Durante o atendimento, foi possível a compreensão de que essa angústia era advinda do próprio menino e, inicialmente, a melhor coisa a fazer foi deixar-nos levar pelas palavras de Cadu e sua posição, nas tentativas de estruturação, é no ponto do não sentido, no tempo da reunião entre a criança e o Outro que a constitui, apresentando-se alienado nesse campo.

Sem problemas para articular as palavras, ele não consegue "desenrolar a conversa". No primeiro encontro, ainda com a família, diz coisas como "o helicóptero vai aqui?", apontando para o teto da sala, repetindo a pergunta, correndo pela sala. Apesar de repetitivo e fora de contexto para nós, seu vocabulário não é restrito e não há uma desorganização sintática, mantendo um encadeamento lógico entre os termos. Porém, Cadu parece não conseguir ir adiante a partir de certo ponto, em que começa a se repetir.

Duas questões nos chamam atenção: a criança não é aceita em um centro de educação devido a seu "comportamento" agitado e por não conseguir brincar com as outras crianças. Aliás, seu brincar é limitado e não consegue estabelecer uma brincadeira; escolhe brinquedos, mas olha para eles sem saber o que fazer. A mãe foi trabalhar em outro país e, apesar de pedidos anteriores, sempre dizia que o menino "não tinha nada". Então, a avó, que agora tem sua "guarda", é quem decide por ele, e a mãe, longe, não se interpõe em suas decisões. A entrada da avó, pela lei, como ordenação simbólica na história do menino dá indícios de uma possibilidade de desencadeamento lógico de significantes que possam ter efeitos constitutivos sobre ele e que o coloquem em outra direção e não em um impasse como sujeito.

A avó materna conta apenas que mãe e pai eram muito jovens quando ele nasceu - prematuro, devido aos "abusos" da mãe; que o menino era colocado em situações de extrema violência e agitação, com brigas entre os pais e os familiares. Atualmente, estão separados e as visitas rotineiras à família paterna são toleradas pela avó materna. Aqui, uma questão chama-nos a atenção: o fato de que a avó materna, no lugar desse Outro constitutivo, começa a repetir os movimentos alienantes da mãe. Todavia, parece-nos que a questão deve ser direcionada a Cadu: qual sua causação que sempre demanda do Outro a não interdição, fazer dele gozo pleno? Como retomaremos, o caminho, a ferramenta, parece-nos ser oferecer significantes - da posição do Outro - a Cadu que lhe tenham um efeito de subjetivação, mas não reter esses significantes; permitir, pela ocor- 
rência em sua fala, que ele os maneje e os combine, em um funcionamento de língua inconsciente, e, então, comece a suportar-se como ser faltante.

Outra fala da avó nos remete ao Cadu bebê: “era um bebê apavorado". Aqui, vale retomarmos, pela ficção, o momento em que o sujeito Cadu nasce, é nascido. Sabemos que a pulsão advém do corpo da criança ao ser tomado pela palavra do Outro, tempo de nascimento do sujeito. Nascer corpo prematuro foi uma primeira tentativa, por escolha, de afastar-se do que lhe apavorava, da angústia diante do corpo e do campo da linguagem parentais que lhe causavam pavor, ao mesmo tempo em que lhe eram constitutivos. Ser um bebê apavorado parecia ser o modo encontrado por ele de denunciar a iminência de seu impasse subjetivo, colocado em uma posição desconfortante e ameaçadora de objeto do Outro, em vez de acolhedora e responsiva. Era levado e colocado em qualquer lugar. Como a questão é anterior à possibilidade de atuar pelas palavras, a possibilidade para Cadu surge quando, por parte da mãe, há um corte, um rompimento: ela vai viver em outro país, o que não caracteriza um abandono. Ao contrário, há indícios de que o menino é mais falado agora do que antes: fala-se sobre suas necessidades e dificuldades, sobre o tratamento, sobre os cuidados com ele. Parece haver um envio de afeto, mesmo à distância.

Nas primeiras sessões, ele se mantém de costas para a terapeuta, sem responder ao que lhe é dito, mexe nos brinquedos, repete muito, sempre em forma de perguntas: "Cê qué dormir?"; "Tem amarelo?"; "Tem verde?”, pegando lápis colorido. Sua entonação de fala tem como característica o fato de alongar a última sílaba e suas frases serem ouvidas tanto como interrogação quanto como afirmação.

Escutá-lo é escutar um ser que não se resolveu diante do Outro: ou pergunta sobre si e sobre o outro, ou confirma sua posição concreta de objeto de desejo do Outro. A função da análise parece ser possibilitar-lhe as questões em vez de respondê-las. Responderlhe tem apenas o efeito de tamponar a falta, impedir os furos por onde poderia advir como sujeito, o sentido. No lugar de instaurar um suposto sentido, desta maneira acaba-se mantendo o não sentido, instaurando a falta fundamental.

Em relação à mãe, segundo a avó materna, ele não sentiu falta dela, pois "continuou do mesmo jeito". O que é compreensível se considerarmos o fato da indiferenciação, pois a questão é mesmo a de instaurar a falta. 
Cadu, ao primeiro contato, nos oferece manifestações de fala primitivas, entonações silábicas, como "psipsipsi", "pispispis" e "tátátâ", que ele entoa quando começamos a conversar. O primeiro passo foi repetir essa língua de Cadu, que o levou a estabelecer uma troca durante os atendimentos. Sua língua é uma língua constituída por sons sem significados, ou seja, por significantes.

Como não era possível entrar em sua cadeia de fala, fomos chamados, por ele, a um diálogo por meio dessa língua primeira, sua lalangue, resíduos de sua linguagem dos primórdios de seu nascer como sujeito, tempo de seus monólogos de berço, na espera pulsional do Outro. Restaurar a si como sujeito é possível na medida em que o próprio Cadu retorna ao seu momento fundante, quando o laço primário foi perdido; mas dá indícios de que pode ser instaurado seja por meio da função paterna presentificada pela ida da mãe, pela figura da avó materna ou, mesmo, como uma função da terapeuta. Ele nos oferece, como ferramenta clínica na construção subjetiva, sua lalangue, de onde nos permite avançar para outras combinatórias, oferecer-lhe outras palavras que podem ser tomadas ao pé da letra, como significantes. Nesse momento, a terapeuta é colocada, por ele, na posição transferencial do Outro em sua constituição.

Suas manifestações de fala se caracterizam por verbalizações melódicas e silábicas com significantes que ele gosta que o outro repita. Há uma intensificação das formas interrogativas com conteúdo limitado (e não forma) e o que se escuta é uma fala que afirma e interroga ao mesmo tempo, colocando quem a escuta em suspensão de sentidos; repete o que lhe é dito como podemos ver no recorte de uma sessão que se segue:

C (Cadu): [Inaudivel...] dormi.

$\mathrm{T}$ (Terapeuta): Você quer dormir?

C: [naudivel].

T: Vamos brincar aqui?

C: [naudivel].

$\mathrm{T}$ : Vamos abrir a sacola com brinquedos?

C: Abri.

T: Você quer abrir?

C: Qué que ábri.?

T: O que é que tem aqui dentro? O que é isso?

C: [Inaudivel...] tem marelo.?

T: Amarelo? Tem um lápis amarelo aí, não tem?

C: Tem verde.

$\mathrm{T}$ : O que mais?

C: E azul.

T: Azul. O amarelo e o azul.

C: Blincá. Qué blincá.?

T: Você quer brincar? Você vai brincar de quê?

C: Qué blincá?

T: Brincar.

C: Ô cê bati??

T: O que é?

C: Tem que bati?? Cadu qué blincá??

T: Você quer brincar? De que você vai brincar?

C: Qué blincá?

T: Brincar.

C: Batê nele. Num vai batê im ninguém.?

A fala vai de inaudível a repetitiva, ecolálica, aparecendo em outras sessões, com os conteúdos de violência e, por vezes, não endereçada. O dizer advém do Outro e nos mostra o tempo de sua cons- 
tituição: de alienação, enodado ao não sentido. Também, nesse recorte, podemos reconhecer o bebê apavorado diante da possibilidade de fazer laço com outras pessoas. A repetição dessas falas e conteúdos, nas sessões seguintes, nos ajudou a situar Cadu frente à possibilidade de um impasse subjetivo, pois atado ao campo do Outro não consegue fazer escolhas, responder questões, reconhecer o que quer, ser causado por um corte. Melhor dizendo, não toma a palavra. Mas a condição de subjetividade que se abre para outras possibilidades, como já ponderamos anteriormente, nos permite sustentar que essa criança não se apresenta ao mundo como um sujeito constituído, pronto e cujo destino seria o destino psicótico.

Tomemos a hipótese clínica sobre Cadu: há indícios de um impasse subjetivo pela posição de alienação manifestada em sua fala e, na dialética com o menino, é preciso apostar no advento do sujeito. Tudo isto, para colaborarmos com a ideia de que na clínica com crianças uma hipótese clínica deve ser feita ao longo do tempo de cuidado, a partir do que ele nos traz regularmente, pois uma criança não está pronta, sob nenhum aspecto.

A primeira demanda de Cadu foi ser inventado na análise; as interrogações características de sua fala foram para nos dizer: "Eu não me sei". É preciso ser sabido por um Outro.

Em suas tentativas de brincar, no manuseio dos brinquedos, ele nos convoca a brincar com ele, o que per- 
mite expandir seu campo simbólico, e, no brincar, ele passa a caminhar nesse campo expandido. Ao escolher brinquedos e se colocar diante deles, Cadu nos espera para realizar, com ele, esse movimento de estruturação. É o momento em que é possível articular o que ele faz com o que ele diz, produzir significações nessa relação com o Outro.

No encontro com essa criança, as direções de tratamento nos apontam para a intervenção pontual em sua cadeia de fala diante daquilo que nos surpreende na clínica com crianças: o Real, a surpresa, o não sentido. Lidar com isto é um trabalho entre a continuidade e a descontinuidade no brincar, no dizer de Cadu, na entonação de suas falas, nas combinatórias de palavras, com o objetivo de não deixá-lo à deriva, assumindo a importante função de Outro que lhe constitui implicando-se em sua história.

\section{Considerações finais}

Discutimos, neste texto, a condição subjetiva de uma criança cujos movimentos de estruturação apontam para seu impasse subjetivo, para a direção em que sua carga pulsional nos faria sustentar a hipótese da possibilidade de ratificação desse sujeito na psicose.

Com base nas manifestações de fala dessa criança e no que, dessas manifestações, poderia apontar para a condição de haver sujeito em constituição como a ecolalia e a entonação dessa fala -, acompanhamos seu percurso de estruturação e os impasses nele inscritos, conforme a hipótese de Vorcaro (1999) e as elaborações desta autora sobre os movimentos de estruturação da criança.

Essa hipótese e as elaborações sobre a estruturação psíquica sustentam a condição da criança como sujeito (do desejo) ainda em constituição, e acompanhar esse percurso como tempo lógico na clínica da criança tem como efeito: primeiro, sustentar a condição da criança de vir a ser sujeito do desejo, impossibilitando, desse modo, seu encerramento em diagnósticos fechados; segundo, nos pontos de impasses escutados na fala da criança, é possível a tentativa de oferecer-lhe a palavra, na posição de agente de subjetivação; e, terceiro, faz-se necessário, na transferência que se instaura pela angústia, frente a um não saber, assumirmos a posição do analista (e de seu desejo de analisar crianças) que se caracteriza pela condição de sujeito suposto saber diante da indagação da criança sobre si mesma - posição essa que deverá ser destituída, em termos longitudinais, na clínica psicanalítica da criança.

Assim sendo, a condição de sujeito em constituição da criança e seu percurso de estruturação psíquica, manifestos pela criança no campo da lingua- 
gem, são direcionadores da experiência nessa clínica psicanalítica da e com a criança.

ON THE CONSTITUTION OF THE SUBJECT: THE SUBJECTIVE IMPASSE

\section{Abstract}

Considering the writing of a clinical case, and focusing on the issue of psychosis in childhood, we will discuss the Lacanian concepts of alienation and separation as fundamental in the subjective construction and in the subject's time of structuration, aiming an approach to the child's situation that arises from the possibility of the subjective impasse as a condition of psychological distress in which the child could not sustain the direction of his instinctual burden.

Index terms: subject; Other; subjective structuration; psychosis; childhood.

SOBRE LA CONSTITUCIÓN DEL SUJETO: EL CONFLICTO SUBJETIVO RESUMEN

Desde la redacción de un caso clínico, centrándonos en el tema de la psicosis en la infancia, discutiremos los conceptos lacanianos de alienación y separación como elementos clave en la construcción subjetiva y en el tiempo de estructuración del sujeto, buscando acercarnos a la situación del niño que surge de la posibilidad de un conflicto subjetivo como condición de un malestar psicológico, en el que el niño no lograría sostener la dirección de su carga instintiva.

Palabras clave: sujeto; Otro; estructuración subjetiva; psicosis; infancia.

\section{REFERENNCIAS}

Bernardino, L. M. F. (2004). As psicoses não-decididas da infância: um estudo psicanalitico. São Paulo: Casa do Psicólogo.

De Lemos, C. T. G. (2007). Da angústia na infância. Revista Literal, 10, 117-126.

Fink, B. (1998). O sujeito lacaniano: entre a linguagem e o gozo (M. de L. S. Câmara, Trad.). Rio de Janeiro: Jorge Zahar.

Lacan, J. (1974-1975). O seminário: RSI. [S.l.]: [S.n.].

Lacan, J. (1985). O seminário, livro 2: o eu na teoria de Freud e na técnica da psicanálise (A. Menezes, Trad.). Rio de Janeiro: Jorge Zahar. (Trabalho original publicado em 1954-1955)

Lacan, J. (2008). O seminário, livro 11: os quatro conceitos fundamentais da psicanálise (M. D. Magno, Trad.). Rio de Janeiro: Jorge Zahar.

Laurant, É. (1997). Alienação e separação I. In R. Feldstein, B. Fink \& J. Marie (Orgs.), Para ler o seminário 11 de Lacan (D. D. Estrada, Trad., pp. 29-41). Rio de Janeiro: Jorge Zahar.

Saussure, F. de. (1995). Curso de linguística geral (A. Chelini, J. P. Paes \& I. Blikstein, Trads., 20a ed.). São Paulo: Cultrix. 
Vorcaro, A. M. R. (1999). Crianças na psicanálise: clínica, instituição, laço social. Rio de Janeiro: Companhia de Freud.

Vorcaro, A. M. R. (2004). A criança na clínica psicanalítica. Rio de Janeiro: Companhia de Freud.

Vorcaro, A. M. R. (2008). Desastre e acontecimento na estrutura. Recuperado em 30 de junho, 2010, de educacaosemhomofobia.files.wordpress.com/2009/03/desenvolvimento-psicossocial-da-identidade-nuh-ufmg-angela-vorcaro.pdf

\section{NOTAS}

1 Língua tal como definida por Saussure (1995): "um sistema de signos distintos correspondentes a ideias distintas" (p. 18), em uma relação de alteridade.

2 É importante atentarmos que esse real - com erre minúsculo - é mesmo o realístico do organismo e não o Real - com erre maiúsculo - que se instaura com a entrada do ser no campo da linguagem.

3 Cf. Lacan (1964/2008): "A natureza fornece, para dizer o termo, significantes, e esses significantes organizam de modo inaugural as relações humanas, lhes dão as estruturas, e as modelam" (p. 28).

cirlanarodrigues@yahoo.com.br Rua das Valsas, 682 38415-426 - Uberlândia - MG - Brasil.

paravidini@ufu.br Avenida Uirapuru, 934 38412-166 - Uberlândia - MG - Brasil.

Recebido em abril/ 2012. Aceito em novembro/ 2012. 